\title{
RESPONSABILIDADES DA ENFERMEIRA NA ASSISTENCIA AO RECÉM-NASCIDO DE ALTO RISCO
}

\author{
Wanda Escobar da Silva Freddi* \\ Doroty Leite Barbieri**
}

FREDDI, W. E. da S. \& BARBIERI, D. L. Responsabilidade da enfermeira na assistência ao recém-nascido de alto risco. Re'v. Esc. Enf. USP, Süo Paulo, 13(1):69-88, 1979.

As autoras comentam a importância da atuação da c'nfermeira na assistência ao recémnascido de alto risco. Fazem consideraçós sofre a responsabilidade da enfermeira na atividade assistencial e educativa a mãe-feto-recém-nascido considerados de alto risco. Procuram destacar a responsabilidade da enfermeira ('m manter aberta as vias de comunicação c'ntre ela e os pais do recém-nascido de alto risco, sempre ajudando-os a vencer a crise tamiliar que se insatalou.

\section{INTRODUÇÃO}

Considera-se que os meses mais importantes da vida de uma criança são os 9 meses antes e o primeiro mês depois do nascimento. Durante o nascimento ocorrem profundas modificações no recém-nascido e, no primeiro dia de vida, ele pode apresentar problemas devidos à incerteza de sua vitalidade neste periodo e aos possiveis efeitos destes no seu desenvolvimento futuro. Pode-se relacionar tais problemas com a vida intra-uterina, com o evolver do parto e com os adquiridos durante as primeiras semanas de vida extra-uterina. Muitos dos problemas que o recém-nascido apresenta são peculiares a este periodo da sua vida e são mínimos ou moderados; de modo geral, estes recém-nascidos necessitam somente de cuidados comuns, evoluindo normalmente. No entanto. alguns podem apresentar problemas graves ou complicação de problemas normalmente moderados. necessitando da intervenção e assistência imediata e eficaz de uma equipe multiprofissional especializada. Estes recém-nascidos são considerados de alto risco e devem permanecer em um berçário de cuidados intensivos.

$\mathrm{Na}$ assistência ao recém-nascido de alto risco a enfermeira é um membro indispensável da equipe multiprofissional. Para tanto, como os demais componentes desta equipe, ela necessita de muito preparo e experiência para dispensar a assistência de enfermagem ideal que cada recém-nascido requer. Precisam adquirir conhecimentos sobre obstetricia e neonatologia. para que possam avaliar a importância e o significado dos fatores maternos e, ao mesmo tempo. compreender os efeitos destes a curto e longo prazo nos recém-nascidos. como por exemplo. doenças e desvios da normalidade.

Segundo GLUCK ${ }^{3}$ os fatores que comumente contribuem para a vulnerabilidade do recém-nascido não referidos a seguir.

* Professor Assistente Doutor responsável pelas disciplinas Enfermagem Obstétrica e Neonatal e Enfermagem Ginecológica da EEUSP.

* Auxiliar de Ensino das disciplinas Enfermagem Obstérica e Neonatal e Enfermagem Gilnecológica da EEUSP. 
- Fatores de alto risco associados à mãe:

1. Idade - menos de $\mathbf{1 6}$ ou mais de 40 anos; - primeira gestação em muIher com 35 anos ou mais.

2. História pregressa da gestação -

- complicações em gestações anteriores;

- história de infertilidade (esterilidade involuntária);

- sensibilização Rh;

- gestações múltiplas anteriores;

- recém-nascidos prematuros anteriores;

- recém-nascidos com más-formações;

- nascimento de crianças com mais de $4.000 \mathrm{~g}$ (mesmo se exames anteriores para diabetes melitus foram negativos).

3. Gestação múltipla.

4. Uso de drogas.

5. Rh negativo ou anticorpos maternos sensibilizados.

6. Hemorragia depois de 20 semanas de gestação.

7. Problemas clínicos maternos:

- toxemia gravídica, hipertensão arterial, doença renal crônica, etc.;

- doenças cardíacas;

- obesidade;

- infecção crônica do aparelho urinário;

- doenças infecciosas (tuberculose, sífilis etc.);

- doenças por vírus (e protozoários) - rubéola, herpes simples (especialmente cervicites), citomegalovirose, toxoplasmose;

- anemia;

- cirurgia durante a gravidez;

- doenças metabólicas (diabetes mellitus);

sulfas, etc.).

- drogas prescritas pelo médico (iodetos, propiltiuracil, rauwolfina,

- Fatores de alto risco associados ao parto ou ao recém-nascido.

1. Duração do trabalho de parto.

- primípara - mais de 24 horas;

- multípara - mais de 12 horas;

- periodo expulsivo - mais de 2 horas.

2. Ruptura das membranas ovulares há 24 horas ou mais.

3. Febre ou infecção materna.

4. Placenta prévia ou descolamento prematuro da placenta.

5. Parto difícil ou, na avaliação da vitalidade do recém-nascido pelo método de Apgar, 5 ou menos, no primeiro minuto de vida.

6. Fórcipe alto ou médio.

7. Cesárea (após um período mínimo de observação).

8. Parto pélvico (após um período mínimo de observação).

9. Peso ao nascer inferior a $2.500 \mathrm{~g}$ ou acima de $4.000 \mathrm{~g}$, independente do período de gestação. 
10. Presença de mecônio no líquido amniótico (sem apresentação pélvica).

11. Gravidez múltipla.

12. Sofrimento fetal.

13. Anormalidades nos testes fetais (eliminação de estriol, fosfatase alcalina. diamina oxidase, etc.).

14. Prolapso de cordão.

15. Síndromes de insuficiência respiratória ou outras doenças respiratórias.

16. Más formações, ou outras anormalidades significantes. do recém-nascido.

17. Evidência de trauma de parto.

18. Droga ou outra depressão no nascimento.

19. Evidência de infecção no recém-nascido.

20. Recém-nascido no pré e pós-operatório.

Considerando estes fatores citados por GLUCK ${ }^{3}$ parece-nos que o profissional de enfermagem ideal para atuar nesta área é a enfermeira obstétrica. A tendência atual da Enfermagem Obstétrica é considerar o ciclo grávido-puerperal como «um ciclo contínuo que inclui a mãe, a filha e a neta, e abrange os períodos pré-natal, trabalho de parto, parto, puerpério, recém-nascido, lactente. pré-escolar, pré-nupcial e pré-concepcional. Inclui, também, os intervalos inter-gestacionais e a menopausa» FREDDI 2. Portanto, a enfermeira obstétrica deverá ser preparada para dar assistência à mulher e seus familiares, tanto no hospital como no domicílio, atingindo. também, a comunidade.

\section{RESPONSABILIDADE DA ENFERMEIRA NA ASSISTENCIA DE ENFER- MAGEM AOS PAIS E AO RECÉM-NASCIDO DE ALTO RISCO}

Podemos dividir as responsabilidades da enfermeira na assistência ao recémnascido de alto risco em duas etapas: na sala de parto e no berçário.

A assistência de enfermagem à parturiente deve ser contínua devido à natureza dinâmica do processo do parto e a possibilidade da ocorrência de complicações a qualquer momento.

Para planejar a assistência de enfermagem à parturiente, cabe à cnfermeira obstétrica:

1. Fazer avaliação inicial da parturiente, levando em consideração a história pregressa e atual do trabalho de parto e parto. Devem-se obter informações sobre: dinâmica uterina antes da admissão na maternidade: condições das membranas fetais; história de perda sangüínea vaginal; duração e descrição dos trabalhos de pario e partos anteriores; idade da gestação atual. A presença de doenças que influem na função placentária constitui informação importante.

2. Avaliar as condiçôes atuais da parturiente: hidratação. grau de fadiga e outros tipos de desconforto que influirão no plano de assistência de enfermagem.

3. Verificar a pressão arterial, o pulso, a respiração e a temperatura; a freqüência. a duração e a intensidade das contrações uterinas; os batimentos cardíacos fetais: a posição e a apresentação fetal; as condições das membranas ovulares: as eliminações vaginais; a dilatação cervical. etc.

4. Observar continuamente o evolver do parto, estando alerta para sinais o sintomas de sofrimento fetal. dificuldades no progresso do parto, sintomas de al- 
terações hematológicas maternas, alterações dos sinais vitais, desidratação e perdas sangüineas anormais.

5. Identificar as necessidades emocionais da parturiente e dispensar assistência de enfermagem especial, visando solucionar o problema identificado, incluindo a assistência específica a cada patologia.

6. Consideraı que as complicações apresentadas pela parturiente atingem também a família. Quando uma familia se defronta com uma complicação, quando deveria haver uma evolução normal e uma situação de felicidade, ela entra em crise. A enfermeira obstétrica precisa estar preparada e ser hábil em ajudar a família a vencer esta crise. Somente o fato de fazê-la saber que a crise existe e que é uma razão real para preocupação poderá, provavelmente, ajudá-la. A identificação da situação de crise da mãe e da família e a intervenção da enfermeira para ajudá-los deve ser um processo contínuo desde a gestação, quando esta é considerada de alto risco, até no domicílio, ultrapassando o periodo neonatal.

7. Orientar os pais sobre a assistência que o recém-nascido deve receber nos casos de parto prematuro, doenças fetais diagnosticadas e eritroblastose fetal. Eles necessitam neste periodo do interesse de outras pessoas e querem saber quais são as possibilidades de sucesso para o seu filho, após ser ele submetido a tratamento.

8. Comunicar os sinais e os sintomas de complicações ao obstetra e ao neonatologista, en tempo hábil, e tomar providências iniciais para corrigí-las, até a chegada destes, principalmente quando problemas fetais são identificados e podem significar a diferença entre a vida e a morte.

Portanto, a observação contínua da parturiente, a comunicação dos dados obtidos ao médico obstetra e ao neonatolgista e a habilidade em exercer as suas funções com decisão e ação rápidas são indispensáveis na assistência de enfermagem à mãe-feto-recém-nascido na sala de parto.

\section{Assistência imediata ao recém-nascido de alto risco}

Cabe à enfermeira obstétrica informar o neonatologista, quando ele não acompanhou o parto, sobre as ocorrências no evolver do mesmo.

KORONES 5 pondera que é conveniente que a primeira avaliação e cuidados do recém-nascido após o parto sejam delgados a uma enfermeira devidamente preparada para essa assistência, que possa consultar um médico qualificado quando houver necessidade. Para o Autor tanto o médico obstetra como a enfermeira obstétrica estão muito envolvidos com a parturiente e não poderão dar toda a atenção que o recém-nascido necessita. A enfermeira (obstétrica ou pediátrica), responsável pela assistência imediata ao recém-nascido, ocupar-se-á apenas deste e estará preparada para desenvolver um plano de cuidado especial para ele.

A enfermeira manterá a sala de cuidados imediatos ao recém-nascido de alto risco com todo equipamento necessário funcionando perfeitamente para um atendimento eficiente, visando:

1. estabelecimento e manutenção da respiração;

2. estabilização da temperatura;

3 . cuidados com o cordão umbilical;

4. cuidados com os olhos; 
5. administração de medicamentos (Vit. $K_{1}$ e outros);

6. identificação;

7. prevenção de infeç̧ão;

8. exame físico sumário do recém-nascido.

A avaliação da vitalidade do recém-nascido será feita pelo Método de Apgar, no $1 .^{\circ}$ e no $5 .^{\circ}$ minuto de vida. A sua aplicação correta fornece meios para avaliação das condições do recém-nascido correlacionadas com problemas pré-natais e o parto.

A aplicação do Método de Apgar é simples, mas exige que a enfermeira tenha conhecimento e habilidade para executá-lo, a fim de que seu resultado seja de confiança e aplicável, como auxiliar do diagnóstico da vitalidade do recém-nascido, no tipo de terapêutica indicada.

0 tipo de assistência neonatal será planejada de acordo com o resultado da avaliação do recém-nascido, pelo Método Apgar. A avaliação dos batimentos cardíacos, respiração, tono muscular, resposta aos reflexos e cor do recém-nascido permitirá a classificação do mesmo em normal ou de alto-risco; este último necessitará. provavelmente, de ressuscitação e assistência especial, com urgência.

A assistência imediata ao recém-nascido de alto risco só será feita pela enfermeira. na ausência ou impedimento do neonatologista, anestesista. médico obstetra ou clínico. Portanto, ela precisa ter «conhecimentos concernentes ao método de ressuscitação, com completa consciência de que poucas enfermeiras aprenderam o seu uso, mas com uma convicção distinta de que muitas crianças poderiam ser salvas se mais enfermeiras pudessem fazê-lo» KORONES ${ }^{5}$.

\section{Assistência mediata ao recém-nascido de alto risco, no berçário}

O recém-nascido de alto risco, quer ou não tenha tido necessidade de ressuscitação na sala de partos, será transferido para o berçário de cuidados especiais ou intensivos, em uma incubadora. A enfermeira levará junto um aspirador, um catéter macio n. 6 ou 8 e, quando necessário, um cilindro portátil de oxigênio.

As informações mais importantes sobre o recém-nascido serão transmitidas à enfermeira do berçário lembrando que nem sempre é possivel ter, na transferência, todas as observações por escrito e que, nesses casos, estas serão enviadas logo após.

A enfermeira do berçário e a da sala de partos, juntas, devem rever a identificação do recém-nascido, o número de vasos umbilicais, o sexo, o atendimento da mãe no pré-natal e a evolução durante o trabalho de parto e parto.

O recém-nascido será colocado em uma incubadora do berçário, deitado de lado. para facilitar a eliminação de muco. Durante o primeiro dia de vida deverá ser observado rigorosamente, mas sem ser incomodado, a menos que se apresente alguma urgência, principalmente nas primeiras duas horas.

Os seguintes cuidados com o recém-nascido de alto risco poderão ser iniciados, se as condições que ele apresenta o permitirem:

- conferir os dados colocados na incubadora, com os do prontuário e os da identificação do recém-nascido (nome da mãe e o sexo, a data e hora do nascimento e a idade gestacional do recém-nascido);

- anotar temperatura, freqüência e tipo de respiração, pulso, atividade, choro, cor, estado nutricional, sinais de trauma de parto, más-formações visíveis; 
- anotar a primeira eliminação de urina e de mecônio no prontuário do recém-nascido;

- observar perda sangüinea, principalmente pelo coto umbilical;

- observar a eliminação de mucosidade; após 30 minutos de vida o pulso e a respiração do recém-nascido devem estabilizar-se e a quantidade de mucosidade oral diminuir; o recém-nascido, geralmente, dorme;

- colocar o recém-nascido em posição correta para melhorar a sua capacidade pulmonar, isto é, em «decúbito dorsal, tórax pouco elevado e a cabeça ligeiramente para trás, ou em decúbito ventral com a cabeça sempre na posição lateral para f'acilitar a eliminação de secreção» RIBEIRO ${ }^{7}$ :

- aspirar a secreção gástrica quando o recém-nascido apresentar mucosidade excessiva; gentilmente, aspirar a secreção nasofaringea; depois colocá-lo na posição anterior e observá-lo cuidadosamente;

- observar o recém-nascido continuamente e aspirar as mucosidades, pois. após dormir 2 a 4 horas, ele entra novamente em um periodo lábil; o pulso e a freqüência respiratória variam, há eliminação de mecônio e a mucosidade oral torna-se abundante;

- dar banho de esponja e a primeira hidratação, de acordo com a prescrição médica, após 6 horas de vida, quando o recém-nascido estará estável; fazer exame físico e neurológico, verificar as circunferência cefálica, toráxica, abdominal, a estatura, etc.

As alteraçôes de um para outro recém-nascido variam e o tempo que ele leva para se estabilizar vai depender da sua patologia, especialmente nas crianças prematuras e nas com asfixia.

Outros cuidados de enfermagem

1. Observação direta do recém-nascido de alto risco.

A observação direta do recém-nascido de alto risco é de importância fundamental. mesmo que este esteja com monitor. Alguns sinais que indicam problemas graves são deteclados melhor e mais precocemente pela enfermeira que o assiste. KORONES ${ }^{5}$ enumera uma série de sinais que não são detectados pelo monitor, citados a seguir:

《 Aceitação da alimentação e aumento de peso.

- Ver, precocemente, quando o recém-nascido regorgita para prevenir a aspiração de alimento ou mucosidade.

- Distensão abdominal; freqüência e característica das fezes.

- Mudanças de atividades (letargia, convulsões, hiperatividade, etc.).

- Icterícia.

- Palidez e cianose percoces.

- Lesões da pele que indicam infecção.

- Alteração na quantidade prescrita de soluções intravenosas.

- Edema.

- Doença respiratória caracterizada por taquipnéia, batimento das asas do nariz e respiração gemente.

- Tipo dos ruidos respiratórios.

- Características e local dos sons cardíacos.» 
2. Observação de outros sinais clínicos de alarme.

A enfermeira estará atenta aos seguintes sinais clínicos de alarme, descritos segundo a Sociedade Brasileira de Cirurgia Pediátrica. (Quadro 1.)

QUADRO 1

Sinais clinicos de alarme.

SINAIS LOCALIZAÇAO DA LESAO $\quad$ DIAGNOSTICO

Secreção bucal espumosa.

Respiração ruidosa - (crises de

Atresia do esôfago.

cianose).

Obstáculo na sondagem gástria.

\begin{tabular}{llll}
\hline $\begin{array}{l}\text { Vômitos biliosos (verdes). } \\
\text { Distensāo abdominal. }\end{array}$ & Obstrução intestinal (alta). & $\begin{array}{l}\text { Atresia. } \\
\text { Estenose. } \\
\text { Ileo meconial. } \\
\text { Peritonite meconial. }\end{array}$ \\
\hline $\begin{array}{l}\text { Falta de eliminação de mecônio. } \\
\text { Distensão abdominal. }\end{array}$ & Obstrução intestinal (baixa). & $\begin{array}{l}\text { Anomalias ano-retais. } \\
\text { Anus imperfurado. } \\
\text { Moléstia Hirschsprung. } \\
\text { (Megacolon Congênito). }\end{array}$ \\
\hline $\begin{array}{l}\text { Dispnéla. } \\
\text { Cianose. }\end{array}$ & Insuficiência respiratória. & $\begin{array}{l}\text { Hernia diafragmática. } \\
\text { Pneumotórax hipertensivo. } \\
\text { Cistos hipertensivos. } \\
\text { Cardiopatias cianóticas. }\end{array}$ \\
\hline $\begin{array}{l}\text { Palidez aguda-choque. } \\
\text { Hemorragia. }\end{array}$ & $\begin{array}{l}\text { Rotura de visceras parenquimatosas. } \\
\text { Moléstias hemorrágicas. } \\
\text { Hemorragia supra-renal. }\end{array}$ \\
\hline
\end{tabular}

3. Temperatura corporal.

Verificar de $4 \mathrm{em} 4$ horas até se estabilizar e, após, de 6 em 6 horas ou de acordo com a orientação do perinatologista.

4. Peso.

$O$ peso deve ser verificado diariamente ou em dias alternados, de acordo $\mathrm{com}$ a orientação médica.

Quando os recém-nascidos estão em berço aquecido ou em incubadora que não tem balança própria, deverão ser pesados envoltos em um cobertor aquecido. A enfermeira deve pesar o cobertor e descontar do total do peso obtido. nascido.

A balança será forrada com papel toalha, substituído ao pesar cada recém-

5. Cuidado com os olhos.

Quando os olhos apresentam irritação pelo nitrato de prata (Método de Credé), limpar com água fervida ou esterilizada morna.

Observar o aparecimento de sinais de oftalmia gonocócica (edema, vermelhidão e secreção ocular), mesmo que o recém-nascido tenha sido tratado pelo Método de Credé. Se a enfermeira verificar o aparecimento destes sinais, avisar imediatamente o neonatologista, a fim de encaminhar material para exame bacterioscópico e para iniciar o tratamento de eleição. Com a alta precoce a mãe deve ser orientada a observar os sinais de oftalmia gonocócica.

Não havendo irritação, o cuidado dos olhos limita-se a inspeção.

6. Cuidado com a boca. 
Inspecionar, diariamente, a boca do recém-nascido de alto risco, visando descobrir precocemente possiveis traumas ou infecções. Outros cuidados serão feitos apenas por indicação médica, direta ou delgada.

7. Cuidado com as fossas nasais.

Proceder à limpeza com fusos de algodão umedecidos, em água fervida ou esterilizada, se necessário. $\mathrm{O}$ uso de cotonetes deve ser muito criterioso.

8. Cuidados com a pele.

Este cuidado varia muito de um para outro hospital. Contudo, o princípio básico desse cuidado é manter a pele limpa, livre de trauma e. conseqüentemente, de infecção.

Esta limpeza pode ser feita com óleo vegetal (de amendoim. amêndoa. etc.) esterilizado, com loção especial ou com água e sabão.

A limpeza com água e sabão pode ser feita usando-se o banho de esponja ou o banho de bacia. A bacia e a toalha usadas no banho serão esterilizadas.

A enfermeira tomará cuidado para não expor desnecessariamente o recémnascido, para conservar a temperatura da água entre $40^{\circ}$ e $43^{\circ} \mathrm{C}$ no banho de esponja e, no banho de bacia, suportável para o bebê.

A escolha do método a ser empregado basear-se-á no equipamento existente no hospital, na habilidade das pessoas responsáveis pelo cuidado do recém-nascido de alto risco (de termo ou de pré-termo) e na reação individual do mesmo.

9. Cuidado com os órgãos genitais.

Limpar, antes das mamadas. ou mais vezes, se necessário, com bolas de algodão embebidas em óleo ou em água esterilizada, aquecidos.

Uma vez ao dia, nos recém-nascidos do sexo feminino. separar os grandes lábios e limpar de cima para baixo com algodão umedecido em áleo ou em água esterilizada: nos do sexo masculino, fazer a retração do prepúcio. sem forçá-lo. limpando a mucosa com óleo ou água esterilizada.

10. Roupas.

A roupa usada deve auxiliar o recém-nascido a manter a sua temperatura corporal.

Nas incubadoras, os recém-nascidos permanecerão apenas de fralda.

As roupas usadas pelo recém-nascido serão lavadas e esterilizadas.

11. Assistência aos pais de recém-nascidos de alto risco.

SLADE ${ }^{8}$ descreve dez mandamentos para a enfermeira que assiste os pais cujos recém-nascidos são de alto risco. Transcrevemos, os mesmos, a seguir:

«1. Conversar com os pais logo após o nascimento.

2. Ser totalmente honesta quando explicar as condições do recém-nascido.

3. Ser otimista.

4. Evitar terminologia médica complicada.

5. Incentivar os pais a ver e a tocar o recém-nascido. 
6. Compartilhar com os pais as novidades boas ou más, a respeito do recém-nascido.

7. Preparar os pais para a morte do recém-nascido quando esta parece inevitável.

8. Encorajar telefonemas e visitas.

9. Preparar os pais para a alta do recém-nascido.

10. Nunca estar ocuparda demais para atender os pais».

Condições que aletam o recém-nascido de alto risco e cuidados necessários

BRIGHTMAN \& CLATWORTHY ${ }^{1}$ comentam que todos os recém-nascidos podem ter dificuldade em conservar suas energias após o nascimento e que, com o de alto risco isto, é imperativo para a preservação da sua vida.

A necessidade de conservar a energia do recém-nascido de alto risco baseia-se nas deficiências que ele apresenta. quer para aqueles cujo periodo de gestação não se completou. quer para os recém-nascidos de termo com baixo peso ou para os que apresentam complicações ou más-formações congênitas. A conservação da energia do recém-nascido de alto risco. nestes casos. basear-se-á nas seguintes necessidades: manutenção da temperatura corporal: manutenção da atividade respiratória: prevenção de infecção; alimentação adequada e movimentação mínima e cuidadosa.

\section{Manutenção da temperatura corporal}

$O$ recém-nascido de alto risco deve ser mantido em um ambiente com a temperatura entre $25^{\circ}$ e $30^{\circ} \mathrm{C}$. Este ambiente. provido de temperatura e ventilação adequadas, contribui para o bem do recém-nascido: o ideal é prover o ambiente com um sistema completo de acondicionamento de ar. mediante o qual se exerça o controle. tanto da temperatura como da circulação de ar. $\mathrm{O}$ ambiente térmico para estes recém-nascidos será neutro, especialmente nos casos em que ele é considerado de pré-termo, visando manter uma temperatura corporal entre $36^{\circ}$ e $37^{\circ} \mathrm{C}$. Porém. não existe temperatura ambiental simples apropriada para os recém-nascidos de diferentes tamanhos e condições físicas: portanto, torna-se necessário controlar periodicamente a temperatura do recém-nascido. As condições que possam alterar o metabolismo do recém-nascido. na tentativa de manter equilibrado o seu meio ambiente. levarão a urn consumo maior de energia para o aumento necessário de oxigênio e de caloria. A imaturidade do sistema nervoso central. a falta de tecido subcutâneo e a proporção da superfície do corpo relacionada ao peso contribuirão para a perda de temperatura corporal. Esse processo é acentuado no recém-nascido prematuro. No recém-nascido pequeno para a sua idade gestacional, a manutenção da temperatura é difícil devido à sua composição corporal e aos diferentes indices metabólicos . Nas outras situações de alto risco. a manutenção da temperatura corporal leva o recém-nascido a gastar sua reserva de energia para compensar o estresse causado pelas mesmas.

O meio mais eficiente para o controle da temperatura. umidade e ventilação. necessárias para estes recém-nascidos. é obtido por aparelhos especiais que são as incubadoras. Contudo é importante lembrar que antes do advento das incubadoras. prematuros conseguiram sobreviver: isto prova que as mais modernas incubadoras 
e os mais eficientes aparelhos de monitoragem não substituem os bons cuidados de enfermagem. MARTINS ${ }^{6}$ distingue, entre os bons cuidados de enfermagem, o interesse por parte da enfermeira; para o Autor, «na falta deste, o funcionamento da incubadora pode deixar de ser adequado, prejudicando, assim, o prematuro por excesso de calor ou frio».

A temperatura da incubadora será regulada de acordo com as necessidades individuais de cada recém-nascido de alto risco, pois cada um responde de modo diferente à temperatura ambiente; deve-se regular a temperatura da incubadora visando manter a do recém-nascido entre $36^{\circ}$ e $37^{\circ} \mathrm{C}$. A temperatura da incubadora só será mudada após fazer-se uma média da temperatura do recém-nascido nas 24 horas precedentes.

A enfermeira precisa estar atenla quanto aos sinais de excesso ou de baixa temperatura. Os sinais de excesso de temperatura são: vermelhidão da pele, inquietação e sudorese. Os de baixa temperatura ambiente para o recém-nascido de alto risco são: choro. tremor e cianose.

A concentração da umidade será determinada. geralmente, pelas condições atmosféricas: a necessidade ou não de umidade é um assunto muito controvertido atualmente. Porém. umidade aquecida é definitivamente indicada quando está sendo administrado oxigênio para o recém-nascido.

\section{Manutençũo da atividade respiratória}

Qualquer recém-nascido que tenha dificuldade respiratória é considerado de alto risco. A gravidade deste recém-nascido está diretamente relacionada com a história da sua vitalidade. a sua maturidade e a causa da sua dificuldade respiratória.

É importante que a enfermeira reconheça os seguintes sinais de problemas respiratórios e o que eles significam:

1. Freqüência e tipo de respiração:

minuto;

- freqüência respiratória neonatal normal: 30 a 60 respirações por

- normalmente a respiração do recém-nascido é diafragmática e abdominal; portanto, retrações intercostais e do apêndice xifóide são consideradas anormais:

- o recém-nascido apresenta respiração nasal e pode apresentar a taquipnéa transitória; esta última é um tipo de respiração rápida que não indica patologia. Ela ocorre em recém-nascido de parto operatório (cesária) ou de parto pélvico. A causa é que o líquido encontrado no pulmão durante a vida fetal não é eliminado. como acontece nos recém-nascidos de parto normal, de apresentação cefálica. Pode durar de 48 a 72 horas ou persistir na primeira semana de vida;

- rítmo respiratório rápido pode ser causado por hemorragia cerebral ou edema cerebral atingindo o centro respiratório, sem anormalidades nos pulmões. Isto causa dificuldade para diferenciar a respiração rápida resultada de condições anormais cerebrais, da atribuida a condições anormais nos órgãos respiratórios propriamente ditos. De vez em quando, ambas as causas estão presentes. 


\section{Ruidos respiratórios.}

A enfermeira atenta poderá ouvir o início de respiração ruidosa, a tosse de defesa. o ruído de excesso de mucosidade, o estridor da laringe, o choro débil insustentável, o grito chamado de choro cerebral, o choro de dor que pode indicar um braço fraturado e outros.

\section{Ausência da respiração ou apnéia:}

- respiração periódica pode estar presente em recém-nascidos prematuros e em recém-nascidos recuperados de anóxia:

- apnéia durante dez segundos não deve preocupar muito:

- em casos de apnéia freqüente e mais prolongada (além de dez segundos) o recém nascido necessita de estímulo do seu centro respiratório (oxigênio e medicação especifica). Geralmente ele apresenta. também, bradicardia;

- ataque de apnéia é quando há ausência de respiração durante 20 segundos, acompanhada de cianose. Este tipo de apnéia ocorre após alimentação por gavage e a causa é a bradicardia ocasionada pela lentidão vaso-vagal.

$\mathrm{Na}$ prevenção de ataques de apnéia a observação contínua do recém-nascido pela enfermeira é obrigatória, mesmo que este esteja em uma incubadora com monitoragem. $\mathrm{O}$ monitor que marca com um sinal audivel os batimentos cardíacos do recém-nascido e que pode ser ouvido em todo o berçário, é de grande ajuda. A bradicardia é o sinal miais precoce de doenças cardio-respiratórias e o alarme do monitor trará a enfermeira para o lado do recém-nascido. instantaneamente.

\section{Respiração ruidosa.}

A respiração ruidosa, com dificuldade aparente na expiração, é freqüente devido à sedação materna, mas. no prematuro. cla pode indicar um primeiro sinal dc síndrome de doença respiratória. com a tríade: aumento dos movimentos respiratórios. retração do esterno e cianose.

\section{Aspiração.}

Quando há um aumento contínuo dos movimentos respiratórios, sem esforço e sem condições de melhora e de estabilidade geral do recém-nascido. a causa mais provável é a aspiração. Quando esta decorre do parto, indubitavelmente, existe um cpisódio de anóxia fetal. Isto é mais problemático quando o líquido amniótico aspirado contém mecônio. Neste último caso, o sinal de asfixia pode mascarar os sinais de aspiração. A aspiração não deverá acontecer após o nascimento.

\section{Pneumonia}

O recém-nascido pode apresentar movimentos respiratórios rápidos devido a uma pneumonia bacteriana intra-uterina adquirida pela inspiração de líquido amniótico, quando as membranas ovulares estão rotas há mais de 12 horas antes do parto. Ocasionalmente, ela é responsável por morte intra-uterina, ou o recém-nascido tein dificuldades respiratórias desde o momento do nascimento.

7. Cianose com ou sem problemas respiratórios.

A cianose é um sinal tardio de dificuldade respiratória. Se ela está presente em um recém-nascido que não apresenta problema no aparelho respiratório, deve. se pensar em defeito congênito do coração. 


\section{Hérnia diafragmática e pneumotórax.}

A hérnia diafragmática é uma causa rara de problemas respiratórios, mas deve ser lembrada. Como, em alguns recém-nascidos, o diafragma não se desenvolveu adequadamente, alguns dos órgãos abdominais ocupam um dos lados do tórax (geralmente o esquerdo), através da falha diafragmática, influindo no funcionamento do pulmão localizado no lado afetado. Este recém-nascido, geralmente. sofre de angústia respiratória desde o seu nascimento.

O pneumotórax apresenta um quadro semelhante ao da hérnia diafragmática. A enfermeira deve estar alerta para o problema de pneumotórax, principalmente quando for usado pressão positiva na ressuscitação do recém-nascido.

Os dois problemas apresentados necessitam de diagnóstico e tratamento rápidos para salvar a vida do recém-nascido.

9. Síndrome de insuficiência respiratória (membrana hialina).

A membrana hialina é um dos problemas sérios nos recém-nascidos prematuros.

Os sinais físicos na membrana hialina alveolar são:

- retração anormal do tórax e do esterno;

- cianose, quando não se mantém o recém-nascido em um ambiente com concentração elevadà de oxigênio;

- freqüência respiratória acima de 60 por minuto;

- gemidos expiratórios.

\section{PREVENÇÃO DE INFECÇĀO}

Levando-se em consideração que os recém-nascidos de alto risco têm baixa resistência à infecção e que a morbidade é um fator que influi no aumento da mortalidade, cabe à enfermeira empregar todos os princípios para prevenir a infecção ou a infecção cruzada. Para tanto, toda a equipe de funcionários deve observar as ténicas empregadas e a limpeza nos berçários.

Cada berçário tem suas normas e técnicas para o cuidado do recém-nascido e o controle de infecção. Porém, o mínimo absolutamente necessário para se prevenirem infecções no berçário é a lavagem das mãos. É claro que as paredes e assoalhos dos berçários e os diferentes fômites dos mesmos devem ser lavados com solução antisséptica e, quando necessário, esterilizados; mas, a fonte primária do organismo patogênico que causa a infeç̧ão nos berçários é a mão da enfermeira e dos outros membros da equipe.

Quando existe boa assistência de enfermagem a infecção é reduzida ao mínimo.

É importante lembrar que, visando a assistência global do recém-nascido, a mãe deve participar ativamente dos seus cuidados; isto é de inestimável valor na interação mãe-filho-família e já se comprovou que não aumenta a incidência de infecção no berçário. 
As técnicas empregadas na assistência do recém-nascido de alto risco visam reduzir ao mínimo a sua morbidade por infecção ou infeç̧ão-cruzada. Nestas técnicas observam-se os seguintes pontos: isolamento, assepsia e antissepsia.

1. Isolamento - $\mathbf{O}$ recém-nascido de alto risco, cuja história indica que tem alto potencial para infeç̧ão, deverá ficar em um berçário de isolamento e o número de pessoas que lhe dispensa assistência deverá ser limitado ao mínimo: funcionários e médico do berçário. Os recém-nascidos de mães que tiveram as membranas amnióticas rotas por 24 horas ou mais, recém-nascidos que nasceram no domicílio ou em condições precárias de higiene e os nascidos de mães com suspeita de doença infecciosa também devem ficar isolados.

2. Tanto os funcionários como os médicos do berçário devem fazer, regularmente, exame físico ,incluindo $\mathrm{RX}$ de tórax, exames bacteriológicos de secreção da nasofaringe e parasitológico de fezes.

3. As enfermeiras que cuidam dos recém-nascidos de alto risco precisam ajudar as mães a sentirem-se mais unidas a seus filhos e a assumirem sua maternidade. Sabe-se que, na maioria dos berçários, não é permitida a entrada das mães no seu interior, mas apenas lhes permitem observar seus filhos através dos visores. Portanto, a enfermeira precisa considerar a maneira de ajudar essas mães dentro deste regulamento.

A enfermeira pode mostrar à mãe que seu filho é aceito por todos, pela maneira como ela o carrega, a forma que lhe fala e como faz comentários a respeito dele.

- O recém-nascido com má-formação congênita aparente não deve ficar separado num canto do berçário para que não seja visto, nem seu defeito deve ser escondido.

- As enfermeiras manterão as vias de comunicação entre elas e os pais do recém-nascido sempre abertas. É comum que os pais procurem esquecer a experiência de uma criança doente ou com má-formação; parece-nos que, antecipadamente, estão se preparando para enfrentar a dor da separação, evitando vínculos afetivos mais profundos. A enfermeira precisa entender este problema; estes pais necessitam compreender que os sentimentos afetivos, geralmente, se desenvolvem gradativamente quando elcs começam a cuidar de seus filhos.

Quando o regulamento permite que a mãe entre no berçário e cuide de seu filho, a enfermeira terá os seguintes cuidados, além dos já existentes, citados anteriormente:

lhe fazer;

- fazer a mãe sentir-se bem recebida no berçário e útil para o seu filho;

- lembrar o nome da mãe e do seu filho;

- responder suas perguntas sobre o peso e os cuidados com o bebê;

- resporder prontamente qualquer outra pergunta que a mãe queira seu filho;

- demonstrar os cuidados que a mãe deve dispensar a seu filho e supervisionar a sua execução; 
- é importante que o pai também possa dar algum cuidado ao seu filho, quando vem ao hospital.

As mães que cuidam de seus filhos são orientadas pela enfermeira quanto ao uso das técnicas empregadas na prevenção de infecção.

$\mathrm{O}$ uso de incubadoras protege o recém-nascido de alto risco da infecção proveniente do ar e dos contactos humanos. As incubadoras devem ser mantidas rigorosamente limpas.

Assepsia e antissepsia

Todo material usado como recém-nascido de alto risco deve ser individual e esterilizado. O material usado com um recém-nascido é considerado contaminado e só deverá ser usado para outro recém-nascido após ser bem lavado com água e sabão e esterilizado.

O equipamento deve ser lavado com antisséptico e arejado em seguida.

\section{Cuidados de antissepsia:}

1. Lavar as mãos. A enfermeira que cuida do recém-nascido de alto risco não usará jóias e relógios e lavará as mãos e ante-braços com antisséptico:

« ao entrar no berçário;

- antes e depois da assistência ao recém-nascido de alto risco;

mesmas:

- antes do preparo das mamadeiras ou da adaptação, de bicos nas

- depois do uso de um lenço;

- depois de atender ao telefone, etc.;

- depois de qualquer limpeza no berçário;

- depois de apanhar qualquer objeto do solo embora não seja o chão

tocado:

- antes de usar objetos de uso comum como balanças, vidros, abrir portas. etc. Para evitar lavar as mãos nestes casos, papel esterilizado poderá ser usado no manuseio dos citados objetos» MARTINS ${ }^{6}$.

Uma das funções da enfermeira é lembrar aos médicos que lavem as mãos e os antebraços ao entrar no berçário e antes de examinar cada recém-nascido.

2. Usar avental, gorro e sapatilhas.

Todo pessoal que entra no berçário é obrigado a usar avental, gorro e sapatilha individuais: médicos, enfermeiras, eletricista, encanadores, faxineiros, etc. Após o uso esse material será colocado para lavar e esterilizar.

$O$ avental é usado exclusivamente no berçário e deve ser de manga curta; a sapatilha será colocada ao entrar no berçário e retirada ao sair do mesmo.

3. Máscara buco-nasal.

A máscara buco-nasal é de pouco valor e, ao mesmo tempo, perigosa. Uma máscara torna-se rapidamente saturada com umidade e com micro-organismos fil- 
trados do ar úmido expirado. Além disso existe uma inclinação de se colocar a máscara sob o nariz ou de ajustá-la com as mãos e assim estas tornam-se contaminadas.

\section{LIMPEZA DO BERÇÁRIO}

\section{Rotina de limpeza diária}

- Assoalho:

- lavar com pano umedecido em antisséptico, diariamente;

- remover o lixo com vassoura úmida.

- Parapeito das janelas e mobiliário;

- limpar diariamente com pano úmido: uma vez por semana lavar com antisséptico.

- Visores:

- limpar diariamente com pano úmido.

- Pias e torneiras:

- arear diariamente.

- Recipientes para fraldas, cestos de papel, latões de lixo, etc.:

- esvaziar diariamente após o cuidado da manhã e da tarde. Usar sacos próprios, de papel ou de plástico, nos cestos de papel e nos latões de lixo.

Incubadores e berços:

- lavar diariamente a parte interna e externa com água e sabão ou antisséptico; usar um pano para cada incubadora;

- após a alta do recém-nascido lavar com água e sabão ou antisséptico e deixar, durante 6 horas, arejando, antes de prepará-la para nova admissão;

- trocar a água destilada esterilizada, diariamente ou com mais freqüência quando necessário. Atualmente muitos autores não aconselham o uso de água destilada, considerando a uma fonte de infecção.

- Material de uso individual:

- limpar com pano úmido ,diariamente, os frascos com bolas de algodão, com soro fisiológico ou água fervida e com óleo;

- esterilizar o frasco e o material contidos no seu interior (bolas de algodão, oleo, etc.) após a alta do recém-nascido. Os frascos devem ser lavados com água e sabão e esterilizados.

- Material de uso geral:

- esterilizar os frascos uma vez por semana e todas as vezes que forem contaminados:

- esterilizar diariamente as pinças serventes e o vidro para a mesma; se a pinça servente for contaminada, esterilizá-la antes de recolocá-la no recipiente; quando se usa antisséptico, as pinças serventes e o frasco deverão ser trocados de acordo com a indicação do mesmo;

- esterilizar os abaixadores de língua, quando estes forem de aço inoxidável;

- limpar com pano embebido em álcool, após o uso em cada recém-nascido, o estetoscópio, a fita métrica e a escala métrica (toesa); 
- lavar o terrnômetro com água e sabão, antes de usar em cada recém-nascido.

\section{- Roupas:}

- lavar separadamente de outras roupas do hospital e esterilizar;

- lavar a roupa que cair no chão;

- fazer o rol de roupa fora do berçário; ao retirá-las do berçário devem ser conservadas dentro dos sacos que estão no «hamper».

\section{Rotina de limpeza trimestral}

Lavar, com solução antisséptica, as paredes e os visores do berçário, pelo menos três ou quatro vezes por ano ou com mais freqüência, se necessário.

\section{ALIMENTAÇĀO}

Os recém-nascidos considerados de alto risco, tanto de termo como prematuros, exigem da enfermeira muita habilidade e paciência na administração de alimentos. $\mathrm{O}$ ideal é a alimentação ao seio; contudo, muitas vezes isto não é possível, sendo necessário utilizar outros métodos para alimentar o recém-nascido.

A enfermeira deve observar atentamente: os reflexos de sucção e de deglutição — se estão presentes ou não; a capacidade de digestão e assimilação — se é pequena, enquanto o total de alimento necessário é grande.

0 médico prescreve o tipo e a quantidade de alimento, mas é a enfermeira que, observando o recém-nascido, reconhece qual é a sua tolerância e qual o método de alimentação que lhe é mais propicio. Portanto, o problema é fazer este alimento chegar ao estômago do recém-nascido. Existirão situações críticas e específicas em que o recém-nascido não poderá ser alimentado pela boca e nestes casos há necessidade de se utilizarem outras formas para resolver o problema. Há diversos métodos para alimentar um recém-nascido de alto risco, de termo ou prematuro, sendo que os geralmente usados são: conta-gotas, colher de chá, mamadeira e gavage.

A alimentação por conta-gotas, colher de chá, mamadeira ou gavage tem a sua técnica própria devendo, cada uma delas, ser adaptada de acordo com as necessidades individuais do recém-nascido.

\section{Conta-gotas.}

Esse método é usado quando o recém-nascido apresenta movimentos de deglutição mas não suga. Este método, embora considerado o melhor por muitos, está praticamente em desuso. Contudo, o ideal é que a enfermeira utilize o conta gotas para dar o primeiro alimento ao recém-nascido; ela dará o alimento gota a gota, observando cuidadosamente se o reflexo de deglutição está presente.

No emprego deste método a enfermeira deve usar conta-gotas com a extremidade protegida por um tubo de borracha de 4 a $5 \mathrm{~cm}$ de comprimento. Ao empregálo terá o cuidado de colocar a extremidade protegida com borracha sobre a língua do recém-nascido, e depositar o alimento, fazendo ligeira pressão sobre a mesma para estimular o reflexo de sucção. Durante a alimentação a enfermeira levantará o recém-nascido, suportando a sua cabeça e os seus ombros com a mão esquerda. Os 
mesmos cuidados serão observados quando se alimenta o recém-nascido com colher de café.

Quando o recém-nascido apresentar dificuldades respiratórias, a alimentação deverá ser interrompida.

Muitas vezes, em recém-nascidos prematuros, a língua, que é muito larga em relação ao tamanho da boca, adere à abóbada palatina e o conta-gotas, a colher de café ou o bico da mamadeira são introduzidos em baixo da mesma. A enfermeira deve verificar se a língua está ou não aderida na abóbada palatina; para tanto, ela sustentará a cabeça do prematuro com os quatro dedos, e com o polegar livre fará leve pressão sobre o maxilar inferior, abrindo-lhe a boca.

\section{Mamadeira.}

O recém-nascido considerado de alto risco poderá ser alimentado com mamadeira com bicos macios, desde que esteja sugando e deglutindo bem.

O tamanho do orifício do bico é muito importante; quando este é muito pequeno o recém-nascido ficará cansado antes de terminar a alimentação; quando é muito grande o recém-nascido terminará rapidamente de sugar, podendo regorgitar após a mamada. Para se verificar se o tamanho do orifício está adequado, inverte-se a mamadeira: o leite deverá gotejar por este orifício.

Quando o recém-nascido que está em incubadora não pode ser retirado para a alimentação, a enfermeira sustentará a cabeça e os ombros do mesmo que permanecerão elevados durante a alimentação. Se o recém-nascido estiver em berço aquecido, será retirado e alimentado ao colo. A enfermeira deverá ter o cuidado de mantêlo aquecido e de não deixar ar entre o gargalo e o bico da mamadeira.

\section{Gavage.}

A gavage é um método usado para introduzir alimento ou para extrair conteúdo gástrico ou duodenal, dependendo da distância em que a sonda é colocada. GO. MES-SANTOS \& ALVARES DE LOS LOBOS ${ }^{4}$ recomendam que a sonda atinja 0 duodeno. A gavage é empregada para conservar o estado geral do recém-nascido.

Os recém-nascidos que necessitam ser alimentados por gavage são:

- os que apresentam aumento de cianose enquanto sugam ou deglutem:

- os que não apresentam reflexo de sucção e de deglutição;

- os que são prematuros com pouco peso e que se fatigam muito durante a sucção, tanto no seio materno como na mamadeira ;

- o prematuro muito desidratado, ao qual é impossivel ministrar a quantidade necessária de líquidos por outro método;

- os recém-nascidos que apresentam lábio leporino, pálato fendido ou outro defeito congênito que interfira com a sucção e a deglutição.

A enfermeira escolherá cste método baseando-se na necessidade do recém-nascido; se a escolha for por ser um método mais rápido, poderá ser um erro.

A gavage pode ser feita por via bucal ou nasal. A gavage por via bucal é feita em cada mamada; deve-se empregar a sonda nelaton número 7 ou 10 . 0 alimento é introduzido na sonda por intermédio de uma seringa, deixando-se o leite descer 
com o peso do êmbolo, pela ação da gravidade. A enfermeira deve usar a técnica correta de gavage e se certificar de que a sonda está realmente no estômago do recém-nascido, antes de introduzir o leite. Para tanto, ela colocará a extremidade livre da sonda em uma cuba com água esterilizada e observará se há formação de borbulhas ou não; se estiver no estomago não deve formar borbulhas.

A alimentą̧āo por gavage, em geral, não oferece perigo durante a introduçāo da sonda, mas sim na sua retirada. Quando a sonda penetra na laringe o recém-nascido reage energicamente, tornando-se inquieto e cianótico. Porém, na retirada da sonda. se a enfermeira não comprimá-la firmemente, havendo líquido retido no seu interior, este poderá cair na faringe e ser aspirado para a laringe.

A gavage por via nasal permanecerá 3 a 7 dias no recém-nascido, quando se usa sonda permanente nasogástrica de plástico flexível. Esta é uma vantagem em nosso meio, onde o pessoal de enfermagem é insuficiente em quantidade e qualidade. A sonda por via oral tem que ser colocada e retirada a cada mamada e sendo o pessoal de enfermagem insuficiente em qualidade, o perigo seria a passagem do alimento para os pulmões durante a retirada da mesma.

A sonda nasogástrica deve ser introduzida pelo médico ou pela enfermeira. Permite a alimentação mais freqüente do recém-nascido.

Este tipo de gavage permite que, quando o recém-nascido apresenta melhora do estado geràl, a alimentação seja dada por mamadeira, sem retirar a sonda nasogástrica. Quando o recém-nascido apresentar sinais de cansaço, a alimentação pode ser completada pela sonda.

\section{Cuidados após a alimentação}

O cuidado de enfermargem depois da alimentação é tão importante quanto o método de administrá-la. Em qualquer dos métodos empregados na alimentação do recém-nascido a enfermeira deverá ter os seguintes cuidados após a mesma:

1. inspecionar o interior da boca verificando se todo o alimento foi deglutido. para evitar que a alimentação retida na boca seja aspirada;

2. permitir a eructação;

3. retirar da pele as gotas de alimentação existente, a fim de evitar, irritação da mesma;

4. deitar o recém-nascido em decúbito lateral, de preferência direito, para evitar que o alimento regorgitado ou vomitado seja aspirado;

5. elevar a bandeja da incubadora ou a cabeceira do berço e conservá-lo elevado durante meia hora. $O$ estômago dos prematuros é mais ou menos vertical em relação ao esôfago e elevando-se a bandeja da incubadora evita-se a regorgitação;

6. Javar a sonda naso-gástrica com 1 a $2 \mathrm{ml}$ de água destilada ou glicose.

\section{Principios geruis sobre alimentação}

1. A primeira alimentação consistirá de água esterilizada ou de solução glicosada a $5 \%$, de acordo com a orientação do perinatologista; se o recém-nascido tolerar água ou solução de glicose. inicia-se a administração de leite. 
2. Não iniciar a alimentação por conta-gotas, colher de café ou mamadeira enquanto o recém-nascido não tiver os reflexos de sucção e deglutição presentes. Os recém-nascidos com idade gestacional inferior a 32 semanas necessitarão, geralmente. de ser alimentados através da sonda gástrica.

3. Verificar se o bico, o conta-gotas ou a colher de café está sobre a língua do recém-nascido.

4. Não alimentar com mamadeira o recém-nascido cuja freqüência cardíaca está acima de 60 batimentos por minuto ou com hipotermia.

5. Os recém-nascidos que necessitam permanecer no berço aquecido ou na incubadora durante a alimentação receberão alimento por mamadeira, conta-gotas ou colher de café e a sua cabeça e ombros permanecerão elevados.

6. Os líquidos ingeridos e as calorias serão controlados, registrando-se cuidadosamente no prontuário; isto auxiliará o médico a esclarecer o motivo básico da causa do recérn-nascido não aumentar peso.

7. A alimentação não é ministrada imediatamente após um tratamento.

8. A alimentação será aumentada gradativa e cuidadosamente. A enfermeira deve informar ao médico a aceitação pelo recém-nascido da quantidade e do método de alimentação, antes de qualquer alteração.

9. A alimentação será considerada satisfatória quando o aumento diário do prematuro for de $15 \mathrm{~g}$ por quilo de peso.

10. Interromper a alimentação quando o recém-nascido apresentar dificuldade respiratória.

11. Diminuir a quantidade de alimento ou suspender a alimentação toda vez que o recém-nascido regorgitar.

12. Incentivar a mãe a amamentar seu filho, após este sugar facilmente o conta-gotas, a colher de café ou a mamadeira. Nunca pedir à mãe que realize alguma ‘oisa que näo seja capaz de fazer.

13. Suç̧ão deficiente depois de um período de alimentação normal deve ser considerado um sinal de alarme e pode ser o primeiro sinal de infecção grave.

14. A alimentação será dada em hora certa. Quando houver mais de um recém. nascido para ser alimentado, iniciar sempre pelo mesmo.

\section{MOVIMENTAÇÃO MINIMA E CUIDADOSA}

A energia, tanto do prematuro como do recém-nascido de termo, considerado de alto risco, é limitada, devendo ser poupada. Sempre que ele é manuseado ou pertubado estará usando esta energia; por esta razão ele deve ser manuseado e pertubado o menos possivel.

A enfermeira, ao fazer o plano de cuidado de cada recém-nascido, planejará para que ele tenha intervalos de repouso. Durante os cuidados de enfermagem observar: os sinais de hemorragia da pele, coto umbilical, fezes, urina, vômitos e outros, evitando, assim, precisar manusear o recém-nascido para verificá-los. 


\section{CONSIDERAÇÕES FINAIS}

Podemos constatar pelo exposto que um dos aspectos mais importantes da assistência de enfermagem ao recém-nascido considerado de alto risco é a prevenção dos fatores que influem na incidência de morbidade da mãe-feto-recém-nascido.

A enfermeira desempenha papel importante na assistência à mãe-feto-recémnascido de alto risco. exercendo atividades assistenciais e educativas nas unidades de pré-natal. centro obstétrico. puerpério e berçário. Para tanto. é imprescindivel que a enfermeira tenha especialização em enfermagem obstétrica ou em enfermagem pediátrica. para poder atuar com segurança e habilidade.

Porém, precisamos estar cientes de que há um déficit destas profissionais e que a sua atuação adequada à realidade do nosso país será mais de administradora. Portando, buscando atender às necessidades assistenciais da mãe-feto-recém-nascido de alto risco, cabe à enfermeira a função primordial de selecionar. treinar e supervisionar o pessoal para trabalhar em berçários de cuidados intensivos.

FREDDI, W. E. da S. \& BARBIERI, D. L. The nurse's responsabilities regarding to the assistance of righ-risk newborn. Rev. Esc. Enf. USP, São Paulo, 13(1):69-88, 1979.

The autohrs refer to the importance of the nurse's performance regarding the care of ihe high-risk newhorn. Different aspects of assistance and education related to this problem are considered. They, also, emphasize the role of the nurse in kecping the parents informed about the conditions of their haby to help them to overcome the actual family crisis.

\section{REFERENCIA BIBLIOGRAFICA}

1. BRIGHTMAN, J. M. \& CLATWORTHY, S. - Care of high-risk infant and his family. In: CLAUSEN, J. J. et alii. Maternity nursing today. New York, McGraw-Hill, 1973. cap. 34, p. 820-67.

2. FREDDI, W. E. da S. - A enfermeira obstétrica no contexto brasileiro. Ent. Novas Dimens., Săo Paulo, 3 (5): 283.8, nov./dez. 1977.

3. GLUCK, L. - Design of a perinatal center. Pediat Clin. N Amer, Philadelphia, 17: 778, nov. 1970.

4. GOMES-SANTOS, F. \& ALVARES DE LOS LOBOS, J. - Rutina de la sala de prematuros del hospital infantil. Bol. méd. hosp. infant., México, 1: 76, 1944.

5. KORONES, S. B. - High-risk newborn infants: the basis for intensive nursing care. 2. ed. Saint Louis, Mosby, 1972. $245 \mathrm{p}$.

6. MARTINS, H. A L. -- Prematuros e recém-nascidos com complicações. Rev. Bras. Enf., Rio de Janeiro, 10 (2): 219, set. 1957.

7. RIBEIRO, E. V. - Causas e prevenção da mortalidade e morbidade neonatal do ponto de vista da enfermagem. In: LISBOA, A. M. \& BARBOSA, L. T. Temas de perinatologia, Brasilia, Senado Federal. Serviço Gráfico, 1970 . p. 59-67.

8. SLADE, C. I. - Working with parents of righ-risk newborn. JOGN Nurs., Virginia, 6 (2): 25, Mar./ Apr. 1977. 